\title{
Work-Family Calendars for Family Sociology Research
}

\author{
By Emily Danforth
}

Philip N. Cohen ${ }^{1}$

and

Jonathan Horowitz

Department of Sociology

University of North Carolina at Chapel Hill

\begin{abstract}
We present an active learning exercise for students in family sociology, gender, or population studies. The main contribution is to introduce a standard work-family history calendar which students use to structure interviews with women ages 34-65. We offer details on the exercise, the attendant research paper assignment, and suggestions for class activities and discussions to enhance the learning experience. Feedback from students suggests the calendar exercise helps organize the interview, recognize patterns in the data, and develop an argument for the research paper. Finally, we present a simple quantitative data manipulation, based on several hundred student calendars, as an example of the potential benefit of aggregating the calendars within or across classes performing the exercise.
\end{abstract}

Prepared for submission to Teaching Sociology in November 2011

${ }^{1}$ Corresponding author: now at University of Maryland, College Park, pnc@umd.edu 
The recent proliferation of student-based learning techniques has led to the creation of class exercises touching on a broad spectrum of learning goals. These include a semester-long project to help students develop a sociological perspective in their day-to-day lives and to connect sociological theory with the "real world" (Pedersen 2010); a class activity to teach students the constructiveness of gender (Berkowitz et al. 2010); and a specialized version of monopoly to teach stratification and its causes (Fisher 2008). The activities enhance students' abilities to bridge sociological abstractness and direct experience and to retain information longer - and students prefer active learning activities to traditional lectures. Students who participate in active learning class exercises also report less anxiety and more enthusiasm about the class subject matter (Segady 1990). Moreover, student-centered forms of teaching and learning lead to better feedback on the quality of teaching and the learning environment (Kember 2009).

We present an active learning project aimed at introductory courses in sociology of the family, gender or population science. This exercise enables students to explore how life history data is collected, recorded and interpreted in the context of studying gender and work-family decision making. The life history calendar method has many research applications and provides many advantages over other survey techniques, including simplicity in gathering complex event data with the use of visual cues, and the development of event sequences to stimulate reflection by respondents (Axinn, Pearce and Ghimire 1999).

Students each choose a woman aged 34-65, interview her and record her family and work history on a work-family calendar. They also conduct a short qualitative interview to develop an account of the woman's life as it involved family and employment decisions. While sharing interesting findings from their interview with other students, they develop a topic for the second part of the project: a research paper. Students connect interesting patterns and experiences that surfaced in their interview or calendar to general sociological patterns of work and family discussed in class. In the process students practice basic interviewing skills, recording demographic data using a standard tool, looking for patterns in family and demographic behaviors, using library database systems, and explaining in their own words how one anecdotal experience relates to broader sociological concepts discussed in class.
The exercise has several practical advantages. First, because it is broken into several parts, students begin working on the project relatively early in the semester. Second, the social relationship with the interview respondent compels students to do justice to their stories and connect them to broader issues. Finally, the chronological components of the exercise build so that the final steps require analyzing, synthesizing and evaluation - the highest levels of learning in Bloom's taxonomy (Bloom and Krathwohl 1956).

Family life educators should create a classroom atmosphere that not only promotes students' learning but also encourages the exchange of experiences, information and viewpoints (Sollie and Kaetz 1992). We believe the exercise presented here achieves that result. The exercise encourages students to open up both to themselves and each other. The variety of student results and responses to the activity help the instructor and the students to emphasize diversity and to create a supportive, dynamic learning atmosphere. Further, gender topics are often a central aspect of courses' focus on the family and interpersonal relationships, mirroring their place in the research literature on work and family issues.

Finally, effective sociological education requires the removal of barriers to incorporating data analysis in sociology courses (Wilder 2010). Although this exercise requires no sophisticated statistical analysis, students must perform some tasks that help to develop basic quantitative literacy skills. Students learn to find patterns in descriptive quantitative data and they learn to describe the patterns in a meaningful way.

\section{WORK-FAMILY CALENDAR RESEARCH PROJECT}

This assignment is designed for introductory classes in sociology of the family, sociology of gender or demography. The exercise works best in a class with 40 students or fewer (or larger courses with smaller recitation sections), so that students can pair up or form small groups to discuss their projects and any issues they are had with their interview.

This exercise has been administered at two large, state universities - one on the West coast of the U.S. and the other in the Southeast. Most students participating in the exercise are women from middle or upper-middle class backgrounds. As outlined here, the scope of the exercise is about equivalent to a standard term paper for an introductory undergraduate course. 
In our experience the last six weeks of the semester are spent discussing or working on various aspects of the exercise. We provide modifications and alterations for the exercise below. Using some of the suggested modifications would expand the amount of work required in and outside of class.

The overarching goal of the exercise is to encourage students to see the intersection of history and biography in women's work-family decision-making. Although the project could be modified, we have limited the interviews to women because their employment behavior has changed much more than men's in the last several decades, and because family decision-making most often revolves around women's employment, while it is assumed men will work for pay. As a result, interviews with men often result in stories with too little variation to for students to meaningfully analyze (as when a man works full time continuously from the end of college until retirement).

Learning goals for the activity include:

- Applying a demographic technique (administering a work-family history calendar) to a real-life context of students' choosing.

- Analyzing life events in calendar form with an interview respondent, and interpreting the respondent's account to describe those experiences in writing.

- Explaining in one's own words how one personal experience relates to broader sociological concepts discussed in class.

- Finding patterns of employment and family trajectories in the work-family calendars collected by different members of the class.

- Becoming familiar with relevant library database and reference systems.

\section{The Exercise}

The project is in two parts. The first part is a worklife calendar filled out with an interview respondent, accompanied by a short written description. The second part is a complete paper on a topic related to workfamily balance, conflict or interaction that makes reference to the work-life interview.

For the interview, students choose a woman aged 34-65 to interview about her work and family life. The age range for the interviewees helps ensure that the women have experienced at least one or more workfamily transitions that are relevant to class topics (e.g. birth, divorce, leaving the workforce, getting a college degree) but are not so old that recalling early transitions will be difficult. Students are instructed to omit the woman's name and any identifying information from the paper and assignment sheets. Students receive a blank "interview fact sheet” for basic demographic information about the respondent and her partner. Students should fill in all the blanks on the fact sheet unless the respondent refuses or cannot answer any questions. In that case, the student should make a note on the fact sheet. The fact sheet serves as a reference for students during interview, to help formulate questions for their respondents as they are filling out the calendar (see below). The fact sheet is included in Appendix A.

The final form that students receive is a simple work-life calendar. The calendar has columns to record a woman's major demographic events (marriage/divorce, births, deaths, and household composition) education, occupation and employment - in rows for each year of her adult life. The students are instructed to complete the calendar with the respondent, asking for clarification of confusing parts or important information that does not fit on the calendar. As they go, the respondent should be asked for her motivations in making work-family decisions. For example, did a particular decision reflect her own ambitions, her husband's job or career needs, her children's needs, or some other factors? Referring to the fact sheet data, for example, a student may ask, "How did you come to that decision? ... Did it matter that your husband had a college degree and you didn't?" Students take notes during the interview but do not need to record it verbatim. A sample calendar with suggested questions is included in Appendix B.

Instructors may ask students to record or tape the interviews to improve students' recall of the interview, however, recording equipment can be expensive and transcription of recorded interviews will certainly increase the amount of time required to complete the project. Additionally, students may have more difficulty locating interviewees who agree to be recorded or taped. For the purposes of the exercise, it is most important that students carefully fill out the work-family calendar and ask follow-up questions about any relevant transitions or events (e.g. birth, divorce, leaving the workforce, etc.).

After the interview, students write a short description of their respondent's story. They should focus on the parts they think are most interesting or relevant to the questions discussed in the course. In doing this description, students may begin looking for a paper topic in their interview. The instructor should emphasize that students try to describe their respondent's perspective without being judgmental (positively or negatively). This is an appropriate stage of the assignment for students to discuss their interviews, and potential research 
topics, in small groups or with the entire class. The opportunity to exchange stories provides a more level playing field than an open-ended discussion about students' opinions or interpretations of the readings.

For the second part of the project, the research paper, students must draw on an issue from their interview, making reference to the interview as necessary, to develop an argument about a work-family problem or important pattern. Students' arguments should include a well-justified and well-reasoned explanation of the cause or consequences of the problem or pattern, or a suggested solution to the problem. And students should try to include their respondent's story as an example.

To explain the context or background of the problem, or support their argument, the assignment requires: a) At least one newspaper article from the previous 12 months (selected from the LexisNexis Academic database or other accessible, standard source); and, b) At least one research article from a peer-reviewed journal - selected from the Sociological Abstracts database. (These research requirements are less than we would typically require for a semester paper, but in conjunction with the interview and the short summary submitted earlier, the requirements are appropriate for our students.)

We offer a class session on how to use library resources and therefore ask the students to use those resources when researching and writing the final paper. Using these resources can help students understand that their respondent's story is but one anecdote; and information from news or other articles can help build their argument. (The specific database requirements also help reduce plagiarism.)

\section{Institutional Review Board Issues}

At the universities where this exercise was administered IRB approval was not required for students' interviews. Universities generally exempt research for class work that will never be published. If instructors plan to aggregate students' interview data for research purposes or publication, IRB approval will be required. The authors of this article received IRB approval to aggregate student data in order to produce the figures in this article.

Instructors may provide students with a form including a brief project description and the instructor's contact information to give to interviewees. This aids students in giving some additional assurance to interviewees that the project is for educational purposes. Such project contact sheets may include: a) the university and class for which the assignment is being completed; b) a brief description of the assignment; c) a statement that the interviewee is not required to participate; d) a statement that all information is for educational purposes only, and so identifiable details will be viewed by the student and instructor only, and; e) contact information for the instructor.

\section{ASSESSMENT}

When evaluating the students' research papers, the assessment rubric requires an argument about a workfamily problem or important pattern. This should include a well-justified and -reasoned explanation of the cause or consequences of the problem or pattern, or a suggested solution to the problem. The students should try to link the argument of their papers to their interviews while recognizing that the interview is just one, anecdotal, case. That is, if the argument is just about the woman the student interviewed, that is not sufficient. In some cases the individual interviewed may represent a counterexample (such as someone who was fortunate not to experience a common problem).

Reconciling and interpreting information from different sources is a key component of the exercise, and features in the assessment rubric (which is included in Appendix $\mathrm{C}^{1}$ ). We note that, depending on the position of the course in the overall curriculum and educational goals of the program, some instructors may want to adjust the weightings in the rubric, for example by increasing the weight given to writing mechanics.

Once students begin to complete the interviews, the instructor facilitates class discussion around the progress of the project and preliminary findings. Doing this enables students to share preliminary findings from their projects and think out potential research paper topics. Each week students informally may present the stories of the women they interviewed in order to initiate class discussion. The instructor should integrate questions about the interviewees into lecture sessions (e.g., marriage and divorce, childrearing, entering and exiting employment).

Students often find the project to be exciting and rewarding. They have reported surprise at learning

\footnotetext{
${ }^{1}$ The first iteration of this rubric was developed by Jonathan Horowitz, when he served as a teaching assistant for the second author.
} 
things about their mothers, aunts, family friends or others, in light of the social patterns and trends they are learning about in the class. For example, a student learned that her aunt's ex-husband convinced or coerced her to quit school and marry him, jettisoning the aunt's promising law career. Later the aunt divorced her husband. The student did not previously know that story and now sees it in the context of women's increasing career opportunities and bargaining power. Some students become particularly interested in the research design aspects of the project; they work hard on their calendars and are excited at the prospect of engaging in more systematic research in the future.

\section{Student feedback}

As we began to prepare this article, the second author solicited written feedback from a class that had just completed the exercise, with questions geared toward the expressed learning objectives above. The responses show that the calendar is one of the most successful aspects of the project, both as a tool to organize the interview itself and as a visualization to make connections between aspects of the respondent's life in the interpretation. As one student wrote,

The work history calendar provided me with a broad range of options to continue to ask my participant about, or choose not to ask about. The calendar allowed for flow of conversation and gave me a starting point when beginning my interview.

Another added, "It provided me with enough direction to continue [the] conversation in order to determine which conflict I was going to choose to write about." The interview respondents also seem to benefit from the calendar format in organizing their thoughts. A student wrote, "I think it was also easier for the interviewee to have a chart like that to fill out instead of just writing it down on a piece of paper."

When it came to analyzing the interviews, students also benefited from seeing the data in calendar form. "I was able to pick up on patterns or interesting points because the information was in calendar form and easy to see the connections," a student said. Said another, "The layout was very well organized. By drawing lines from the age in which each event occurred, [it] made it easier to be able to see patterns."

Finally, for learning to see the intersection of biography of history - specifically in the case of workfamily interactions for women, a number of students found the exercise revelatory. "I think it was very effective," wrote one, "because I had to research broader sociological concepts and apply them to this specific interviewee example, which I believe helped me understand the material better." In light of the course material, one student wrote, "I was surprised by how many issues my respondent had that face all females, including myself.” In conclusion, one student summarized:

This project really made me aware of the issues that each gender faces within the work and family, especially the issues that women face. I am now more aware of the restrictions and problems that many women face, that without this project, I would not have been as aware of.

\section{ALTERATIONS, ADAPTATIONS AND EXTENSIONS}

This exercise has gone through five iterations. One of the biggest changes made after several years was to drop the prohibition against students interviewing family members or close friends. The intention of the requirement to interview someone less familiar was to help students consider objectivity in social research, but it also made it more difficult for students to find people to interview and delayed them starting their work. And, as it turns out, many of the students now feel they get more out of the exercise by treating it as a sort of family history project.

The students enjoy sharing stories and experiences from their interviews and calendars with the class. As a group, the interviews represent a potential combined research project, akin to a larger research study. To help illustrate this, after the second author used the exercise in several large classes, we compiled 341 individual work-family history calendars into a single dataset. We used the data to develop descriptive graphs for use in class. Although the data are not from a representative sample, many of the themes from the course present themselves in the data.

Figure 1, for example, shows the employment rates for women interviewed by the students, according to their marital status and age. (Because each respondent contributes information for each year of her adult life - an average of about 30 data points per person - such graphs can be produced even in much smaller classes.) Such a data manipulation may help a class see the research project in aggregate form and imagine its place in the larger stream of sociological research - for example by integrating qualitative and quantitative sources of data. 
Alternatively, instructors might assign students to groups and have the groups aggregate their individual interview data. The instructor could then provide students with some nationally representative statistics and ask the students to look at how their group's "sample" compares to the national average for things such as educational attainment, age or racial composition. Such extensions would help students explore the role of small samples in qualitative research, and allow them to work together while gaining experience manipulating simple datasets.

Another variation involves assigning students to groups and asking each group to focus on women with a specific characteristic (e.g. non-White respondents, older respondents, women without a college degree, etc.). After each student completes her/his interview the groups may look for common themes, patterns, or work-family events and share these findings with the rest of the class.

\section{CONCLUSIONS}

This work-family calendar exercise, with its attendant research paper component, offers an active learning experience to students in courses on family sociology, gender, or population studies. It connects well with common themes in these courses, which often engage work-family conflicts, trends and gender issues. Because the final product is an individual research paper, it satisfies the goal of many instructors to include such an assignment in their courses.

The work-family calendar exercise aims to demonstrate by experience a common research technique - a life-history calendar interview - and challenges students to see an interview respondent at the intersection of history and biography, as a sociological case study. When conducted in a small group or class, the exercise offers the opportunity to share stories and reflect on their research implications - as well as the personal insights students have gained. Finally, in the aggregate, the exercise provides the opportunity for students and instructors to collaborate on a larger project, to combine the calendar data and analyze it in more depth.

\section{References}

Axinn, William G., Lisa D. Pearce and Dirgha Ghimire. 1999. "Innovations in Life History Calendar Applications." Social Science Research 28(3):243264.

Berkowitz, Dana, Namita N. Manohar, and Justine E. Tinkler. 2010. "Walk Like a Man, Talk Like a Woman: Teaching the Social Construction of Gender." Teaching Sociology 38(2):132-43.

Bloom, Benjamin S. and David R. Krathwohl. 1956. Taxonomy of educational objectives: The classification of educational goals, by a committee of college and university examiners. Handbook 1: Cognitive domain. New York: Longmans.

Fisher, Edith M. 2008. "USA stratified monopoly: A simulation game about social class stratification." Teaching Sociology 36(3):272-82.

Kember, David. 2009. "Promoting student-centered forms of learning across an entire university." Higher Education 58(1):1-13.

Pedersen, Daphne E. 2010. “Active and Collaborative Learning in an Undergraduate Sociological Theory Course.” Teaching Sociology 38(3):197-206.

Segady, Thomas W. 1990. "Teaching the Classics." Teaching Sociology 18(2): 214-17

Sollie, Donna L. and Julie F. Kaetz. 1992. “Teaching University-Level Family Studies Courses: Techniques and Outcomes.” Family Relations 41(1):18-24.

Wilder, Esther Isabelle. 2010. “A Qualitative Assessment of Efforts to Integrate Data Analysis throughout the Sociology Curriculum: Feedback from Students, Faculty and Alumni." Teaching Sociology 38(3):226-46. 
Figure 1. Percent of women employed, by marital status and age

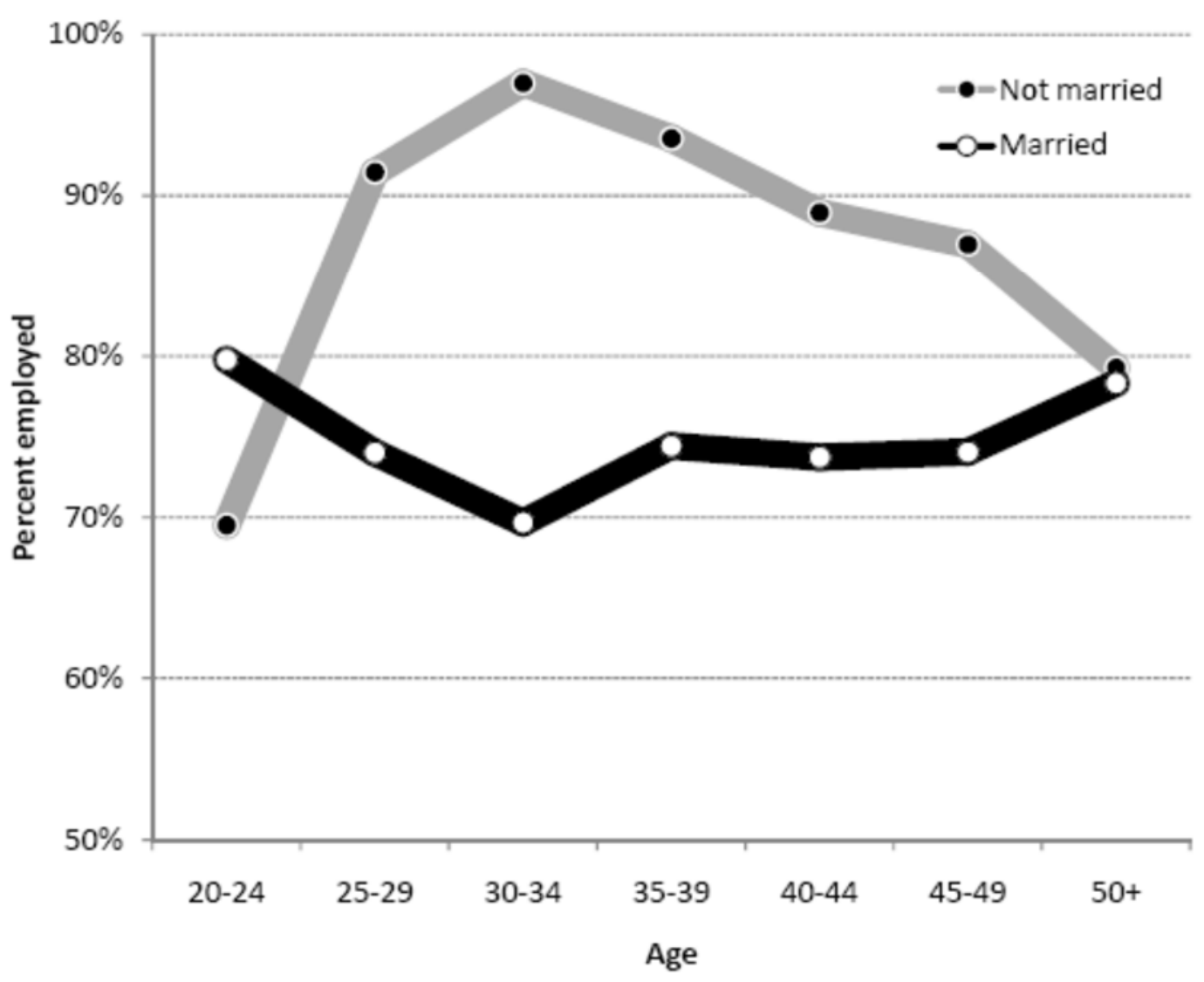




\title{
Appendix A. Interview Fact Sheet
}

The following questions to be asked of each respondent, and her current spouse if applicable.

\author{
Age: \\ Race/ethnicity (check all that apply): \\ White \\ Black \\ Latino (specify): \\ Asian (specify): \\ Pacific Islander (specify): \\ American Indian (specify): \\ Highest level of education attained:
}

Religion:

Place of birth if outside U.S.:

-- Age at immigration:

Current occupation:

Current work status (full-time / part-time): 
Appendix B. Sample Work-Family Calendar

\begin{tabular}{|c|c|c|c|c|c|c|c|c|c|}
\hline & \multicolumn{9}{|c|}{ WORK-FAMILY CALENDAR } \\
\hline & \multicolumn{2}{|c|}{ Family events } & \multicolumn{4}{|c|}{ Who lived in the home? } & \multicolumn{3}{|c|}{ Education / Employment } \\
\hline Age & $\begin{array}{l}\text { Marriage/ } \\
\text { Divorce }\end{array}$ & $\begin{array}{l}\text { Births/ } \\
\text { deaths }\end{array}$ & $\begin{array}{c}\text { Husband } \\
\text { partner }\end{array}$ & Parents & Children & Others & School & Occupation & Work time \\
\hline 17 & & & & & & & High Sc. & & \\
\hline 18 & & & & & & & I & & \\
\hline 19 & & & & & & & $\mathrm{~V}$ & Cook & Full Time \\
\hline 20 & & & & & & & & I & I \\
\hline 21 & & & & & & & & I & I \\
\hline 22 & & & & & & & & I & I \\
\hline 23 & & & Tom & & & & & I & I \\
\hline 24 & Married Tom & & I & & & & & 1 & I \\
\hline 25 & & & I & & & & & I & $\mathrm{V}$ \\
\hline 26 & & Jen born & 1 & & Jen & & & I & Part time \\
\hline 27 & & & 1 & & 1 & & & I & I \\
\hline 28 & & & 1 & & I & & & $\mathrm{V}$ & $\mathrm{V}$ \\
\hline 29 & & Dad died & 1 & Mom & 1 & & & & \\
\hline 30 & & & $\mathrm{~V}$ & 1 & 1 & & & & \\
\hline 31 & Divorced Tom & & & 1 & I & & Nurse sch. & & \\
\hline 32 & & & & 1 & I & & 1 & & \\
\hline 33 & & & & $\mathrm{~V}$ & $\mathrm{~V}$ & & $\mathrm{~V}$ & & \\
\hline
\end{tabular}

Based on the history in this calendar, the following questions are suggested. Note that the questions are open-ended, but organized around the education/employment transitions, with reference to the other events on the calendar.

1. About your decision to enter full-time work after high school...

a. How did you make the decision to start work after high school?

b. What alternatives, if any, did you consider?

2 . At the time that you reduced your hours as a cook to part-time...

a. How did you and Tom make the decision that you would work part time?

b. What was your husband's work situation?

c. Did you consider either continuing to work full-time, or leaving paid work altogether?

3. When you stopped working for pay at age $28 . .$.

a. What was the situation with your mother living with you?

b. Did the fact that your mother was living with you at that time affect your decision regarding work?

4. When you went back to school for nursing...

a. What was the sequence of events around your divorce from Tom and returning to school?

b. How did you make the decision to go back to school?

c. What alternatives, if any, did you consider?

d. I see Jen was about 6 years old at that time, what was her school and daycare situation then... did that affect your decision? 


\section{Appendix C. Work-Family Calendar Assignment Assessment Rubric}

Maximum possible points: 30

Quality of the argument (possible points: 12)

1. Clearly stated and developed sufficiently?

2. Reflective of course understanding?

3. Incorporating interview, news and academic sources, and logically addressing differences that arise from these sources.

Quality of evidence (possible points: 12)

1. Sufficient for the argument?

2. Used appropriately?

3. Drawn from interview, news and academic journal sources?

Quality of writing (possible points: 6)

1. Clear and concise?

2. Logical mechanics (e.g., transitions)?

3. In an appropriate tone?

Possible demerits (maximum 5 points each)

1. Off topic

2. Extreme deviation from suggested length

3. Citations or bibliography not appropriate or consistent

4. Grammar and spelling 